\title{
A Long Breast Cancer Remission without Standard Therapy
}

Dani $\mathbf{M}^{1}$, Pinder S, Baum $\mathbf{M}$ and Fentiman $\mathbf{I S}^{4^{*}}$

${ }^{1}$ Breast Unit, Guy's Hospital, UK

'Guy's \& St Thomas' NHS Foundation Trust, UK

'University College Hospital, UK

${ }^{4}$ Research Oncology, Guy's Hospital, UK

Keywords: Breast cancer; Spontaneous remission; Hormone replacement therapy; Alternative medicine

\section{Introduction}

There have been many claims of remissions in cancer patients taking a variety of non-conventional therapies but few stand up to objective clinical and pathological scrutiny. These apparent miracle cancer cures can often be dismissed because histological proof of malignancy was missing in the first place, or the patient forgot to mention that he or she was taking conventional therapy as well.

Krutchik et al reported spontaneous regression of metastatic breast cancer in a patient with pleural and bone disease [1]. This occurred in the absence of any endocrine treatment systemic chemotherapy. It was postulated that there might have been an immunological mechanism involved. The patient relapsed after a remission lasting 6 years [2].

Another spontaneous remission was reported by Handforth et al. [3] in a 70-year-old woman with metastatic disease causing dysphagia, respiratory insufficiency, and bilateral vocal cord paralysis [3]. This occurred 7 years after mastectomy and there was spontaneous partial remission of symptoms before death, with no systemic or local therapy being given. Autopsy revealed both inflammatory and metastatic infiltrates of the vagus nerves, with disproportionate demyelination. The authors questioned whether resolution of cancer associated inflammation within vagus and phrenic nerves may have caused the spontaneous remission.

Ventegodt et al. [4] claimed that on two different occasions, breast cancers reduced in clinical size by $>50 \%$ during a holistic session [4]. As they admitted, both patients had the tumours excised so it was not possible to determine if they were actually "healed" by the holistic treatment. Nevertheless, one should not have a closed mind since some of the effective drugs in use have arisen from the study of folk remedies such as the vinca alkaloids, derived from the periwinkle family of flowers. We therefore report a case history which at face value suggests a dramatic complete response of histologically confirmed breast cancer to an unorthodox regimen.

\section{Case History}

The patient was first seen at Guy's Hospital Breast Unit in January 1992. At that time she was aged 60, married with two children, and had been on hormone replacement therapy, HRT, (Prempak-C) for 10 years. Prempak-C is a sequential form of combined HRT comprising 0.625 mg conjugated estrogens taken daily and a progestogen (norgestrel) taken on days 17-28. For the previous two years she had been aware of a painless lump in the left breast, and recently had noticed skin dimpling. There was no family history of breast cancer.

On examination she was a slim woman with skin dimpling in the left lower outer quadrant and deep to this a mass $2.2 \times 2 \mathrm{~cm}$, with no deep attachment. In the left axilla there was a $2 \mathrm{~cm}$ mobile node. A clinical diagnosis of carcinoma was made and a freehand core biopsy, Bioptycut $^{\text {tw }}$ taken at that time.

This confirmed the presence of an invasive breast cancer, provisionally grade II. The longest core of tissue was $9.5 \mathrm{~mm}$ of which $7 \mathrm{~mm}$ was infiltrated by tumour. No vascular invasion was seen. She returned to the results clinic where she was given the diagnosis and informed that the carcinoma was suitable for breast conservation therapy comprising wide excision, axillary clearance and external beam radiotherapy. At that time the patient would normally have has staging investigations including chest $\mathrm{x}$-ray, full blood count and liver and bone profiles but she did not return for these investigations. She was reluctant to undergo any surgery and went to a Holistic Medical Clinic in Tunbridge Wells. There she was given a course of nutritionally orientated therapy and when examined at the Holistic Clinic in February 1992 the breast lump was said to be the size of a pea but no dimensions were recorded.

The "polytherapy" she received was carefully documented and is described in Table 1. She attributed the clearance of the lymph glands to jumping on a trampoline for 15 minutes a day. Also, at the beginning she used two "ozone therapy" treatments, applying a "light shaker" to the breast and underarm lumps for about 30 minutes a day. The "polytherapy" was given for approximately 6 months (Figures 1A-1H).

She remained well, not taking any medications, and was not aware of any breast problems. In March 1997, five years after the histological diagnosis, she was seen by MB for a second opinion at University College Hospital. At that time there was no evidence of cancer in the left breast and ultrasound did not show any abnormality. Subsequently, with the patient's permission, the original biopsy specimen was reviewed and the clinical notes re-examined. The histology was confirmed as showing an invasive breast cancer, with tumour cell nuclei positive for both oestrogen and progesterone receptors.

It was noted however that she had been taking Hormone Replacement Therapy (HRT) at the time of the original diagnosis. On contacting the patient's general practitioner it became apparent that this had been stopped in January 1992, at the time of original diagnosis.

The patient was referred back to Guy's Breast unit in August 2008 with abdominal discomfort and on examination had $11 \mathrm{~cm}$ abdomino-pelvic mass and $1.5 \mathrm{~cm}$ left Supraclavicular Fossa (SCF) lymphadenopathy. No abnormality was palpable in the breasts or axillae. Imaging of breast and axilla did not pick up any abnormality. Ultrasound of the SCF showed an $18 \times 10 \mathrm{~mm}$ node sitting on top of the left subclavian artery, just lateral to the left internal jugular vein.

*Corresponding author: Ian Stuart Fentiman, Research Oncology, 3rd FloorBermondsey Wing, Guy's Hospital, UK, Tel: +44 (0)20 7848 8300; E-mail: ian.fentiman@gstt.nhs.uk

Received July 14, 2015; Accepted August 22, 2015; Published August 29, 2015

Citation: Dani M, Pinder S, Baum M, Fentiman IS (2015) A Long Breast Cancer Remission without Standard Therapy. J Clin Case Rep 5: 569. doi:10.4172/21657920.1000569

Copyright: ( 2015 Dani M, et al. This is an open-access article distributed under the terms of the Creative Commons Attribution License, which permits unrestricted use, distribution, and reproduction in any medium, provided the original author and source are credited. 
Citation: Dani M, Pinder S, Baum M, Fentiman IS (2015) A Long Breast Cancer Remission without Standard Therapy. J Clin Case Rep 5: 569. doi:10.4172/2165-7920.1000569
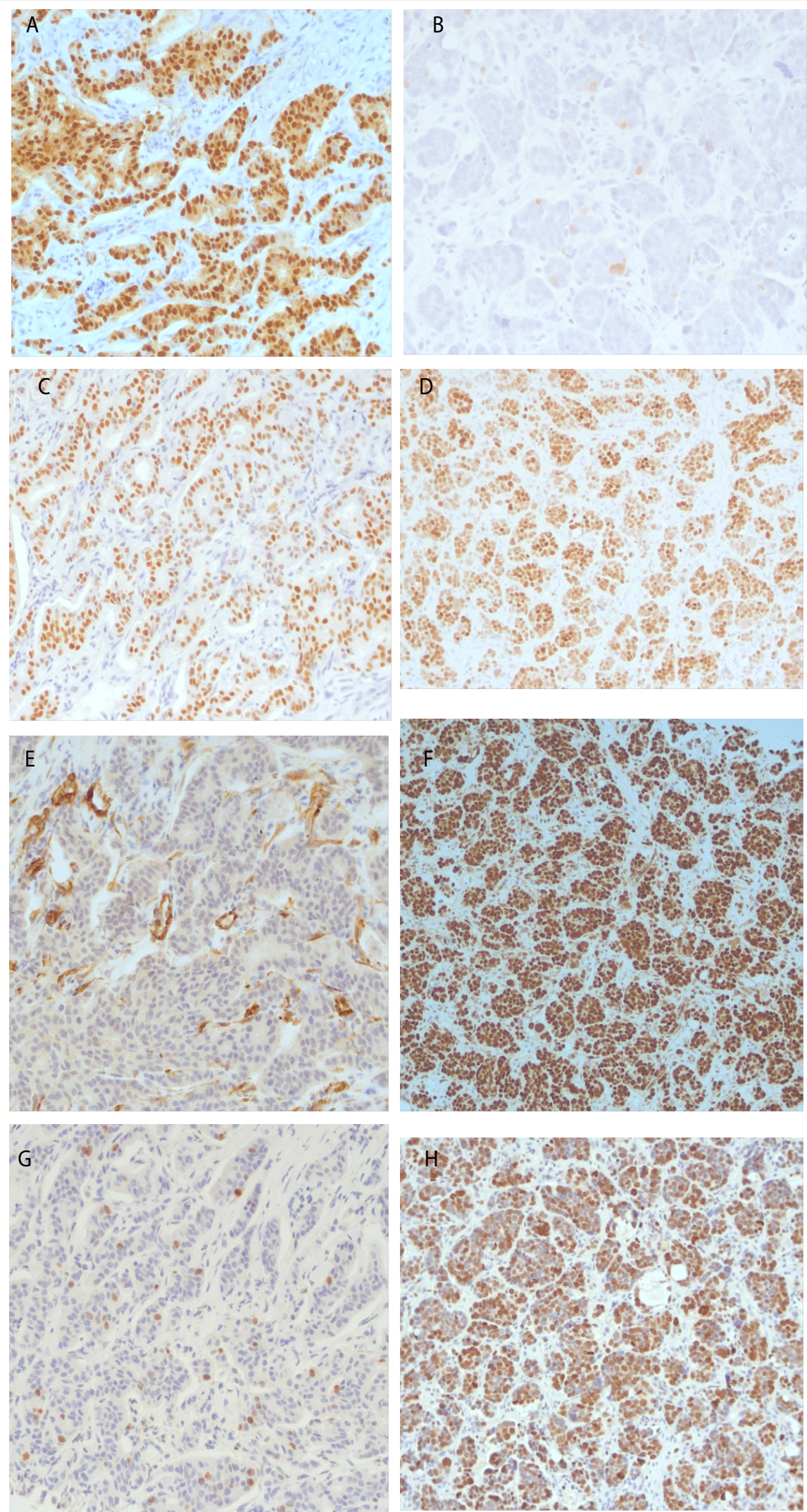

Figure 1A: Breast core biopsy from 1992 immunostained for progesterone receptor (PgR). B: Lymph node biopsy 2008 showing no immunostaining for progesterone receptor. C: Breast core biopsy from 1992 immunostained for estrogen receptor (ER). D: Lymph node biopsy 2008 showing immunostaining for estrogen receptor (ER). E: Breast core biopsy from 1992 immunostained for WT1 F: Lymph node biopsy 2008 immunostained for WT1. G: Breast core biopsy from 1992 immunostained for MIB1. H: Lymph node biopsy 2008 immunostained for MIB1. 


\begin{tabular}{|c|c|}
\hline \multicolumn{2}{|l|}{ Amino acids } \\
\hline L-methionine $500 \mathrm{mg}$ & 1 daily \\
\hline L-cysteine 500 mg & 1 daily \\
\hline L-arginine $500 \mathrm{mg}$ & 3 daily \\
\hline L-tyrosine $500 \mathrm{mg}$ & 2 daily \\
\hline Taurine $500 \mathrm{mg}$ & 3 daily \\
\hline \multicolumn{2}{|l|}{ Minerals } \\
\hline Zinc citrate $1.5 \mathrm{mg}$ & 2 daily \\
\hline Magnesium EAP2 & 2 daily \\
\hline \multicolumn{2}{|l|}{ Magnesium ethanolamine $692 \mathrm{mg}$} \\
\hline \multicolumn{2}{|l|}{ Elemental magnesium $100 \mathrm{mg}$} \\
\hline Selenium complex $200 \mathrm{mg}$ & 5 daily \\
\hline Organic sulphur(methylsulphonylmethane) $500 \mathrm{mg}$ & 4 daily \\
\hline \multicolumn{2}{|l|}{ Enzymes } \\
\hline Lo-pH enzymes & 3 daily \\
\hline Biozyme & 4 daily \\
\hline \multicolumn{2}{|l|}{ Quercitin 200 mg } \\
\hline \multicolumn{2}{|l|}{ Vitamin C $200 \mathrm{mg}$} \\
\hline \multicolumn{2}{|l|}{ Parain $20 \mathrm{mg}$} \\
\hline \multicolumn{2}{|l|}{ Bromelain $20 \mathrm{mg}$} \\
\hline \multicolumn{2}{|l|}{ Rutin $60 \mathrm{mg}$} \\
\hline \multicolumn{2}{|l|}{ Cyanocobalamin $10 \mathrm{mg}$} \\
\hline Catalase complex & 1 daily \\
\hline \multicolumn{2}{|l|}{ Vitamins } \\
\hline B3 (nicotinamide) $500 \mathrm{mg}$ & 3 daily \\
\hline B5 $500 \mathrm{mg}$ & 2 daily \\
\hline E 250 iu & 3 daily \\
\hline Potassium ascorbate & Work up to $30 \mathrm{~g}$ \\
\hline \multicolumn{2}{|l|}{ Miscellaneous } \\
\hline \multicolumn{2}{|l|}{ DMG complex } \\
\hline Dimethyl glycine & 1 daily \\
\hline Dimethylsulphoxide synergistic agent (tablespoon) & 1 daily \\
\hline Thymax lamb thymus $62 \mathrm{mg}$ & 2 daily \\
\hline Flax oil (tablespoon) & 3 daily \\
\hline Bee pollen (tablespoon) & 2 daily \\
\hline Chlorella & Work up to 30 daily \\
\hline Bee propolis tablets & 2 daily \\
\hline Aloemed Aloe vera juice & $2 \mathrm{oz}$ daily \\
\hline
\end{tabular}

Table 1: Details of polytherapy.

Competed tomography CT scan of chest, abdomen and pelvis showed a $2.5 \mathrm{~cm}$ probable metastasis in segment 6 of the right liver lobe. There was extensive para aortic and aorto-caval lymphadenopathy, the largest node measuring $3.5 \times 2.2 \mathrm{~cm}$. In addition, there was a large omental deposit seen in the lower anterior abdominal wall measuring $11.8 \times 5.3 \mathrm{~cm}$ and extensive tumour seen throughout the pelvis encircling the left side of the rectum and extending onto the back of the uterus and both ovaries.

The core biopsy of left SCF node was compared with core biopsy histology from Guy's Hospital from the left breast from 1992. The breast core consisted of fibrous breast tissue infiltrated by invasive carcinoma of provisional (core) grade II $(2,3,1)$ and no special type. This was morphologically different from the lesion in the left SCF lymph node from 2008 which consisted of fibro-fatty tissue infiltrated by carcinoma forming small nests of pleomorphic proliferative malignant cells. Immunohistochemical profile of the two tumours was slightly different and is summarised in Table 2. In particular the lymph node stained

\begin{tabular}{|c|c|c|}
\hline Immunohistochemical profile & Breast (1992) & SCF node (2008) \\
\hline Ck7 & + ve & + ve \\
\hline Ck20 & $-v e$ & $-v e$ \\
\hline ER & $7 / 8$ & $7 / 8$ \\
\hline PR & $8 / 8$ & $3 / 8$ \\
\hline HER2 & $-v e$ & $-v e$ \\
\hline TTF1 & $-v e$ & $-v e$ \\
\hline Ck5 & $-v e$ & $+v e$ \\
\hline Ck14 & $-v e$ & $-v e$ \\
\hline MIB1 & $5 \%$ & $80 \%$ \\
\hline p53 nuclear reactivity & Weak (in 50\% of cells) & Strong (in 100\% of cells) \\
\hline WT1 & - ve & + ve (100\%) \\
\hline
\end{tabular}

Table 2: Immunohistochemical profile of the two tumours.

strongly for WT1 which was absent in the breast tumour, the node showed $100 \%$ staining for p53 nuclear reactivity compared with only $50 \%$ of cells in the primary. Furthermore only $5 \%$ of cells in the breast cancer were MIB1 positive whereas $80 \%$ of cells in the lymph node were positive.

Although it was possible that these two biopsies were from a primary breast lesion which has altered morphology and immunoprofile over time, on balance the findings would favour these being separate primary lesions; the immunoprofile and morphology of the first lesion being in keeping with a breast primary carcinoma and the second suggesting a gynaecological (ovarian) malignancy.

The patient was referred to the oncologists for palliative chemotherapy, but refused this treatment so that no further evaluation or characterisation of the metastatic disease was possible. Her condition deteriorated and she died of metastatic carcinoma in January 2009.

\section{Discussion}

It is indeed possible that amongst the plethora of alternative therapies she had been taking that there was an active principle which contributed to the disappearance of the breast cancer. In particular dimethylsulphoxide (DMSO) has been used as a cryopreservative by cell biologists and also as a differentiating agent in developmental biology. Thus in theory this could have induced dedifferentiation of malignant cells to a more benign phenotype [5].

A more plausible explanation however is that the cancer disappeared because of the withdrawal of the hormone replacement therapy. Jena et al. [6] reported a patient with locally recurrent breast cancer, who went on to develop distant metastases [6]. At that time she was taking hormone replacement therapy (HRT) and after this was stopped she underwent complete radiographic resolution of disease with no other treatment.

Neoadjuvant endocrine therapy for patients with large or inoperable breast cancers has been shown to be associated with a small but consistent likelihood of achieving a complete pathological remission in approximately $2 \%$ of cases $[7,8]$. Hypophysectomy used to be performed as a treatment for advanced breast cancer and Brugge et al. [9] described a patient with metastatic disease who then went into a spontaneous remission as a result of metastatic disease destroying the pituitary gland [9].

It is likely that because she had a slow-growing endocrine sensitive breast cancer that estrogen withdrawal enabled this apparent long-term spontaneous remission. If nothing else this anecdote illustrates that breast cancer can be cured, that is the patient lives long enough to die from other causes, in selected cases by a "softly softly" approach that 
Citation: Dani M, Pinder S, Baum M, Fentiman IS (2015) A Long Breast Cancer Remission without Standard Therapy. J Clin Case Rep 5: 569. doi:10.4172/2165-7920.1000569

does not depend on surgery, radiotherapy and cytotoxic chemotherapy but on the capacity of the malignant phenotype to revert to the norm by modification of the cytokine microenvironment [10].

\section{References}

1. Krutchik AN, Buzdar AU, Blumenschein GR, Lukeman JM (1978) Spontaneous regression of breast carcinoma. Arch Intern Med 138: 1734-5.

2. Ross MB, Buzdar AU, Hortobagyi GN, Lukeman JM (1982) Spontaneous regression of breast carcinoma: follow-up report and literature review. Surg Oncol 19: 22-24.

3. Handforth A, Nag S, Robertson DM (1984) Polyneuropathy with vagus and phrenic nerve involvement in breast cancer. Report of a case with spontaneous remission. Arch Neurol 41: 666-668.

4. Ventegodt S, Morad M, Hyam E, Merrick J (2004) Clinical Holistic Medicine: Induction of Spontaneous Remission of Cancer by Recovery of the Human Character and the Purpose of Life (the Life Mission). The Scientific World Journal 4: 362-377.
5. Marks P, Richon V, Kiyokawa H, Rifkind A (1994) Inducing differentiation of transformed cells with hybrid polar compounds. A cell cycle-dependant process. Proc Natl Acad Sci 91: 10251-10254.

6. Jena R, Wilson CB, Earl H (2001) Complete resolution of metastatic breas cancer by withdrawal of hormone replacement therapy. Clin Oncol ( $R$ Coll Radiol) 13: 200-201.

7. Cameron DA, Anderson EDC, Levack $P$ (1997) Primary systemic therapy for operable breast cancer -10 year survival data after chemotherapy and hormone therapy. Br J Cancer 76: 1099-1105.

8. Gazet JC, Coombes RC, Ford HT (1996) Assessment of the effect of pretreatment with neoadjuvant therapy on primary breast cancer. $\mathrm{Br} \mathrm{J}$ Cancer 73: 758-762

9. Brugge RJ, Van Dongen JA, Stofberg AM (1965) Spontaneous remission of metastasized breast cancer due to pituitary metastases. Ned Tijdschr Geneeskd 109: 506-510.

10. Schipper H, Turley EA, Baum MA (1996) New biological framework for cancer research. Lancet 34: 1149-1151. 